\title{
GmLEA2-1, A LATE EMBRYOGENESIS ABUNDANT PROTEIN GENE ISOLATED FROM SOYBEAN (GLYCINE MAX (L.) MERR.), CONFERS TOLERANCE TO ABIOTIC STRESS
}

\author{
Zhikun Wang, Qiang Yang, Yupeng Shao, Binbin Zhang, Aiyun Feng, \\ FANLI MENG and WeNBIN Li*
}

Key Laboratory of Soybean Biology in Chinese Ministry of Education/Key Laboratory of Biology and Genetics \& Breeding for Soybean in Northeast China, Ministry of Agriculture (Northeast Agricultural University), Harbin, China

(Received: December 06, 2017; accepted: June 4, 2018)

\begin{abstract}
Late embryonic proteins (LEA) gene family was abundant mainly in higher plant embryos, which could protect the embryos from the damage caused by abiotic stress, especially drought and salt stresses. In the present study, GmLEA2-1 was cloned from soybean leaf tissue treated by $10 \%$ polyethylene glycol 6000 (PEG6000). The results of quantitative real-time PCR (qRT-PCR) revealed a variety of expression patterns of GmLEA2-1 in various tissues of soybean (root, stem, leaf, flower, pod, early embryo and late embryo). GmLEA2-1 gene shared a lower sequence similarity with other typical LEA genes of same group from different species, but similar functions. Overexpression of GmLEA2-1 in transgenic Arabidopsis thaliana conferred tolerance to drought and salt stresses. The fresh weight and dry weight of seedling, the primary root length and the lateral root density of transgenic Arabidopsis plants were higher than those of wild type Arabidopsis (WT) under drought and salt stresses. Cis-acting regulatory elements in the GmLEA2-1 promoter were also predicted. These data demonstrate that GmLEA2-1 protein play an important role in improving drought and salt tolerance in plants.
\end{abstract}

Keywords: GmLEA2-1 - Stress tolerance - Soybean-promoter - Transgenic Arabidopsis thaliana

\section{INTRODUCTION}

Late embryogenesis abundant (LEA) proteins were first discovered in cotton 30 years ago [9]. They are expressed during the later stages of embryo development (postabscission) in plant seeds are and induced in vegetable tissues in the presence of abiotic stress such as drought, low temperature, salt and abscisic acid (ABA) [15]. With the improvement of deep sequencing technology, an increased number of LEA genes have been identified [3, 22, 23, 26, 29]. LEA proteins are categorized in seven distinct families, according to the results of Battaglia's group on the basis of their amino acid sequence similarities and conserved motifs [4].

The main physical characteristic of most LEA proteins are that they are generally hydrophilic and intrinsically unstructured or disordered. The structural feature of LEA proteins suggested that some of LEA play an important role in the regulatory pathway of defending adverse environment in the organism. The functions of some

\footnotetext{
*Corresponding author; e-mail address: wenbinli@neau.edu.cn
} 
LEA groups have been studied in details $[5,6,12,17,28,30]$. However, compared with other categories of LEA proteins, LEA_2 is rather more hydrophobic and possesses relatively stable three-dimensional structure [16]. The biological functional studies related to LEA_2 family are considerably fewer than in other groups. Only some of the atypical LEA_2 group genes from several different species have been investigated. The overexpression of atypical LEA_2 genes could improve the stress tolerance to drought and salt in transgenic plants $[18,29]$. The difference both the hydrophobic content and the structure between LEA_2 group proteins and other LEA groups is not obvious. It was compelling for us to elucidate weather LEA_2 gene from soybean plays different or similar role in withstanding adverse environment.

In the present study, we aimed to isolate a novel member of LEA genes from soybean and characterize the role of GmLEA2-1 in regulation tolerance to abiotic stresses. We investigated the expression of GmLEA2-1 induced by abiotic stresses and the resistance to salt and drought stresses in transgenic Arabidopsis overexpressed GmLEA2-1. Cis-acting regulatory elements in the GmLEA2-1 promoter were also predicted. These data could further define the role of GmLEA2-1 in the responses to abiotic stresses and the potential involvement of GmLEA2-1 in the genetic modification of plants in enhanced tolerance to drought and salt.

\section{MATERIALS AND METHODS}

\section{Plant materials and growth conditions}

Soybean seed (Glycine max (L.) Merr.) 'Dongnong 50' was obtained from Northeast Agricultural University (Harbin, China). To analyze the tissue-specific expression of GmLEA2-1, the root, stem, leaf, flower, pod, early embryo, and late embryo from soybean plants were harvested, frozen in liquid nitrogen and stored at $-80{ }^{\circ} \mathrm{C}$. To analyze the expression profile of GmLEA2-1 under abiotic stress conditions, soybean plants, with the first fully expanding trifoliate leaves, were transplanted into $1 / 4$ Murashige and Skoog (MS) liquid medium supplemented with 10\% PEG6000 and $100 \mathrm{mM} \mathrm{NaCl}$, respectively, 1/4 MS liquid medium without PEG6000 and $\mathrm{NaCl}$ as control. The leaves were sampled at $0,3,6,9,12,15,18,21,24$, and 27 hours after transferring.

Seeds of Arabidopsis thaliana (Col-0), were cultured on 1/2 MS medium with 2\% sucrose for three weeks at $21-22{ }^{\circ} \mathrm{C}$ with a $16 \mathrm{~h} / 8 \mathrm{~h}$ (day/night) photoperiod and $60-70 \%$ relative humility. Then, the young seedlings were transplanted on fertilized soil and grown in the same conditions.

\section{Cloning and sequence analyses of GmLEA2-1}

The total RNA was isolated from soybean seedlings treated by 10\% PEG6000 using RNAiso Plus ${ }^{\mathrm{TM}}$ kit (TaKaRa, Japan). The first strand cDNA was synthesized accord- 
ing to the protocol of the First Strand cDNA Synthesis Kit ${ }^{\mathrm{TM}}$ (TaKaRa, Japan). To obtain the open reading frame (ORF) of GmLEA2-1, PCR was performed with the primers 5'-TCGCTTGGATCACTGATCTCATCTC-3' and 5-'GCCAGTAATAACGAGCTCCAATTCTTCAAT-3'. The PCR products were purified and cloned into the pMD18-T vector (TaKaRa, Japan) for sequencing. The isoelectric point and molecular mass predictions were estimated using the compute $\mathrm{Pi} / \mathrm{Mw}$ toll. Analysis of protein hydropathy was done by constructing hydropathy plots with the Kyte and Doolittle algorithm. Motif analysis was performed using the Pfam program. Sequence similarities were determined using the BLAST program and the GenBank database on the NCBI web server. Sequence alignment was performed with DNAMAN.

\section{GmLEA2-1 expression analysis}

Total RNA was isolated from soybean leaves using RNAiso Plus ${ }^{\mathrm{TM}}$ (TaKaRa, Japan). qRT-PCR was performed on a Chromo4 Real-Time PCR System (Bio-Rad, USA) using SYBR Green PCR Master Mix Reagent (TaKaRa, Japan). The primers used for GmLEA2-1 amplification were 5'-TTAGAGGAAGGGGAACAGGTTACAC-3' and 5'-TGCCCATCAGAACTCAGAAAG-3'. Soybean Actin4 gene was used as the internal control. The primer used for Actin4 gene amplification was 5'-GTGTCAGCCATACTGTCCCCATTT-3', and the reverse primer was 5'-GTTTCAAGCTCTTGCTCGTAATCA-3'. Three replicates of each reaction were

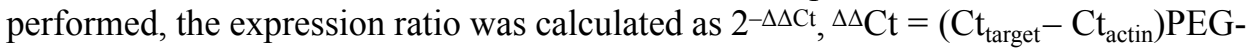
$\left(\mathrm{Ct}_{\text {target }}-\mathrm{Ct}_{\text {actin }}\right) \mathrm{CK}$.

\section{Overexpression of GmLEA2-1 in Arabidopsis}

GmLEA2-1 cDNA was sub-clone into the binary vector pCAMBIA3301. The recombinant plasmid was transformed into Agrobacterium tumefaciens strain L4404 and was introduced into Arabidopsis using the floral dip method. Transgenic Arabidopsis plants were tested by PCR, using the primers 5'-CACTATCCTTCGCAAGACCC-3' and 5'-TGAATCGCAGTAACGTCAGC-3'.

For drought tolerance assay in MS medium, one-week-old seedlings were transformed to $1 / 2 \mathrm{MS}$ medium with $0,100,200,300 \mathrm{mM}$ of mannitol. Photographs were taken after 10 days, and root lengths were measured. The up-part of seedlings was collected and used to measure proline content.

For salt tolerance experiment in MS medium, one-week-old seedlings were transformed into $1 / 2 \mathrm{MS}$ medium containing $0,50,100,150 \mathrm{mM}$ of $\mathrm{NaCl}$, respectively, for two weeks to evaluate salt tolerance in MS medium. The fresh weight and dry weight were measured, respectively. And, the average root length and the lateral root density were calculated afterward. 


\section{Biomass and proline accumulation}

The proline content was tested according to Liu's method [21]. The content of proline was calculated as $\mu \mathrm{g} / \mathrm{g}$ using a proline standard (L-proline, Sigma-Aldrich Inc., MO, USA).

\section{Statistical analysis}

The survival rate, fresh weights, dry weights, root lengths, lateral root density and proline content were subjected to Student's $t$-test analyses using SPSS 12. All of the experiments were biologically repeated three times.

\section{RESULTS}

\section{Isolation and sequence analysis of GmLEA2-1}

A cDNA containing $1024 \mathrm{bp}$ was isolated from soybean leaves treated with $10 \%$ PEG6000 for 6 h, named GmLEA2-1. GmLEA2-1 encoded a putative 320 amino acids with a calculated molecular weight of $35.65 \mathrm{kDa}$ and a theoretical $\mathrm{pI}$ of 4.8. GmLEA2-1 was predicted to have highly hydrophobic structure with the exception of the N-terminal region [19]. The GmLEA2-1 protein contained a "Lea_2" motif (PF03186), which was classified into subgroup 5C (D-95) according to Battaglia's classification of LEA protein [7, 8]. Further analysis showed that GmLEA2-1 contained a lower percentage of polar amino acids (48.7\%) and higher percentage of non-polar amino acids $(25.8 \%)$ than other groups' LEA proteins [13, 29]. All these characteristics were consistent with those of other members of subgroup $5 \mathrm{C}$ $[13,29]$.

The deduced amino acid sequences shared very low identity with a typical group of LEA 2 (Fig. 1a). GmLEA2-1 was more closely related with At2g446060 (67.69\%) than At1g01470 (13.53\%) and At2g46140 (16.17\%). The homologous rate between GmLEA2-1 protein and soybean endogenous LEA_2 protein D95-4 was only 8.2\% [23].

\section{Expression of GmLEA2-1 in different tissues of soybean and under drought and salt stress}

GmLEA2-1 was strongly expressed in root and pod, and relatively lower in stem and leaf (Fig. 2a), which was consistent with the previous microarray and EST data [20]. Interestingly, GmLEA2-1 expression in early and late embryos was strikingly low, in accordance with the results, of the expression of At2g44060 [17]. 
a

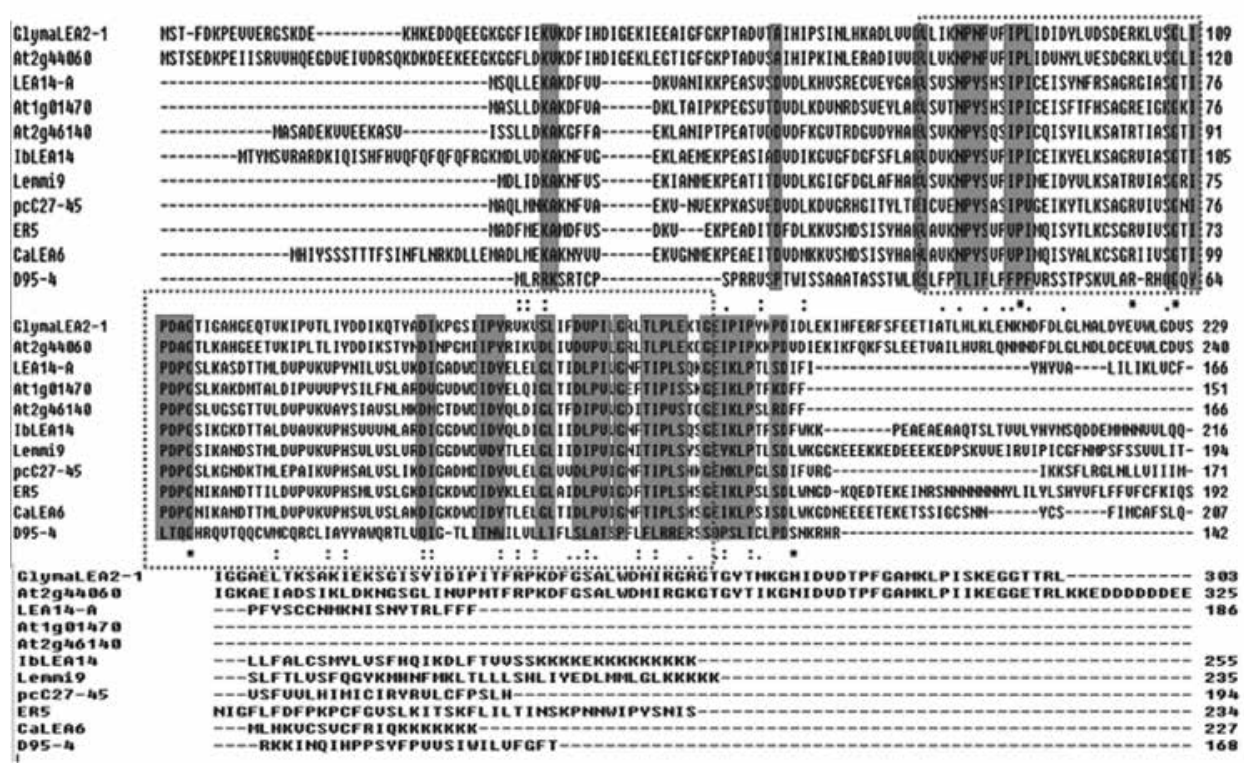

b

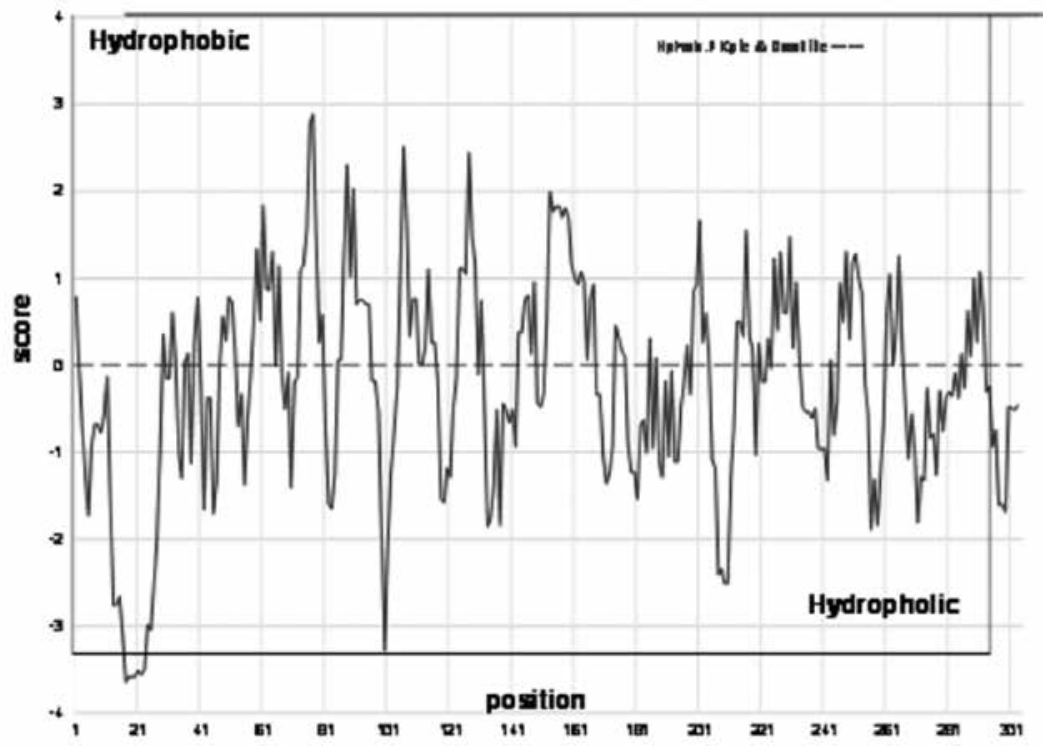

Fig. 1. Multiple sequence alignments, phylogenetic tree and hydropathicity plot for deduced amino acid sequences of soybean GmLEA2-1 and other closely related plant proteins. a - Multiple sequence alignments of GmLEA2-1 with other LEA14 proteins. The conserved "LEA_2" motif (PF03168) is boxed. $\mathrm{b}$ - Hydropathicity plot of the deduced GmLEA2-1 amino acid sequence analyzed using the KyteDoolittle algorithm 
The mRNA level of GmLEA2-1 in soybean leaf under 10\% PEG6000 treatment did not exhibit obvious reduction or increase until soybean plants suffered from 9 hours dehydration (Fig. 2b). The peak of mRNA accumulation occurred at 12 hours from the initiation of stress. Along with the consistent stress of PEG6000, the level of GmLEA2-1 mRNA began to drop down gradually. Additionally, $100 \mathrm{mM} \mathrm{NaCl}$ treating 8 hours resulted in increased accumulation of GmLEA2-1 to a maximum level (14-fold) (Fig. 2c). The above results indicated that GlmLEA2-1 might play important roles in the responses to abiotic stress.
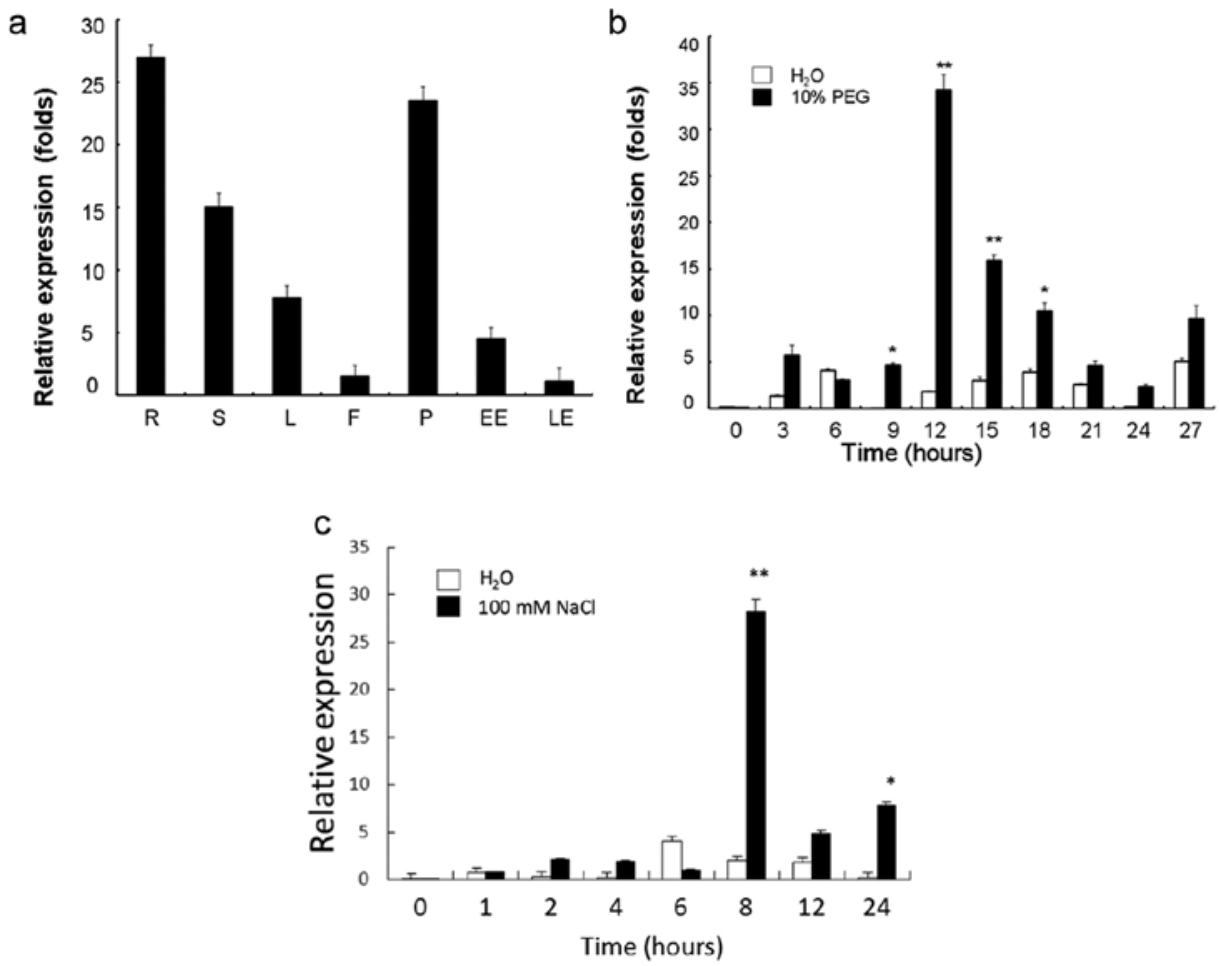

Fig. 2. Expression patterns of GmLEA2-1 in various tissues and under different dehydration conditions. a - Tissue-specific expression of GmLEA2-1. Total RNA was extracted from roots (R), stems (S), leaves (L), flowers (F), pods (P), early embryos (EE), and late embryos (LE). b - GmLEA2-1 transcripts accumulation levels in response to $10 \%$ (v/v) PEG 6000 treatment. c - GmLEA2-1 transcripts accumulation levels in response to $100 \mathrm{mM} \mathrm{NaCl}(\mathrm{v} / \mathrm{v})$. The ACTIN gene was used as a control gene. Each data point is average of three biological replicates and bars indicate SD. *Indicates significant differences in comparison to the wild type at $\mathrm{P}<0.05, * *$ the same at $\mathrm{P}<0.01$ 
ZHIKUN WANG et al.

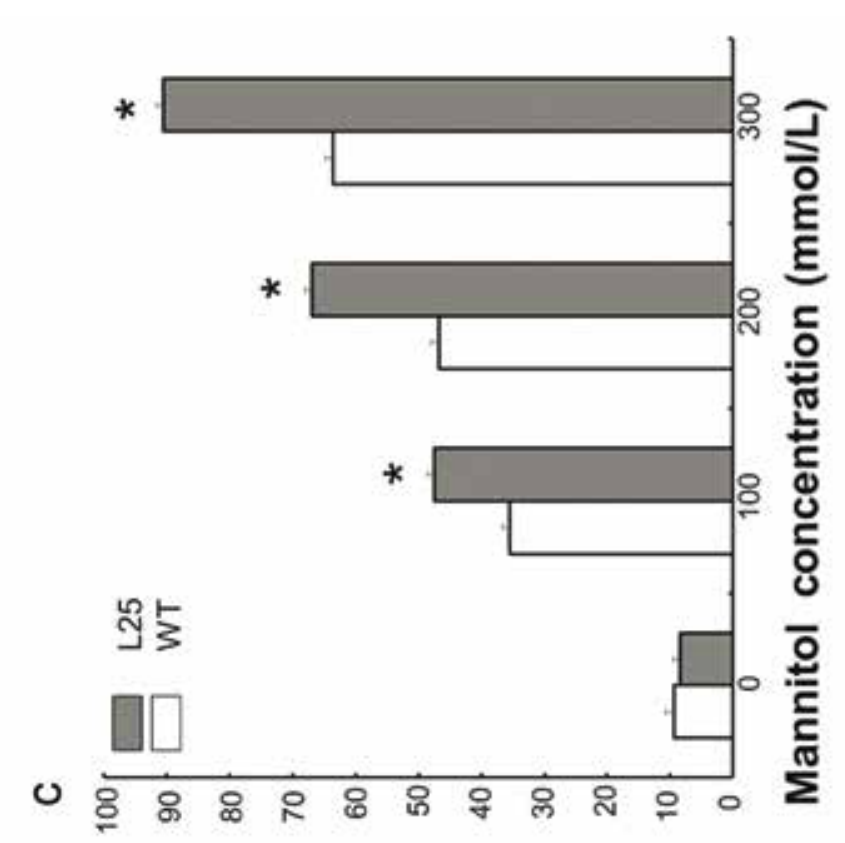

苛总递

空 훙

邪

运层

홍

की

政语

응

政

$\approx .0$

要

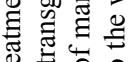

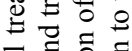

क्ष

言击

(1)

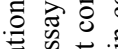

政

$(6 / 6 r)$ əu!ןodd
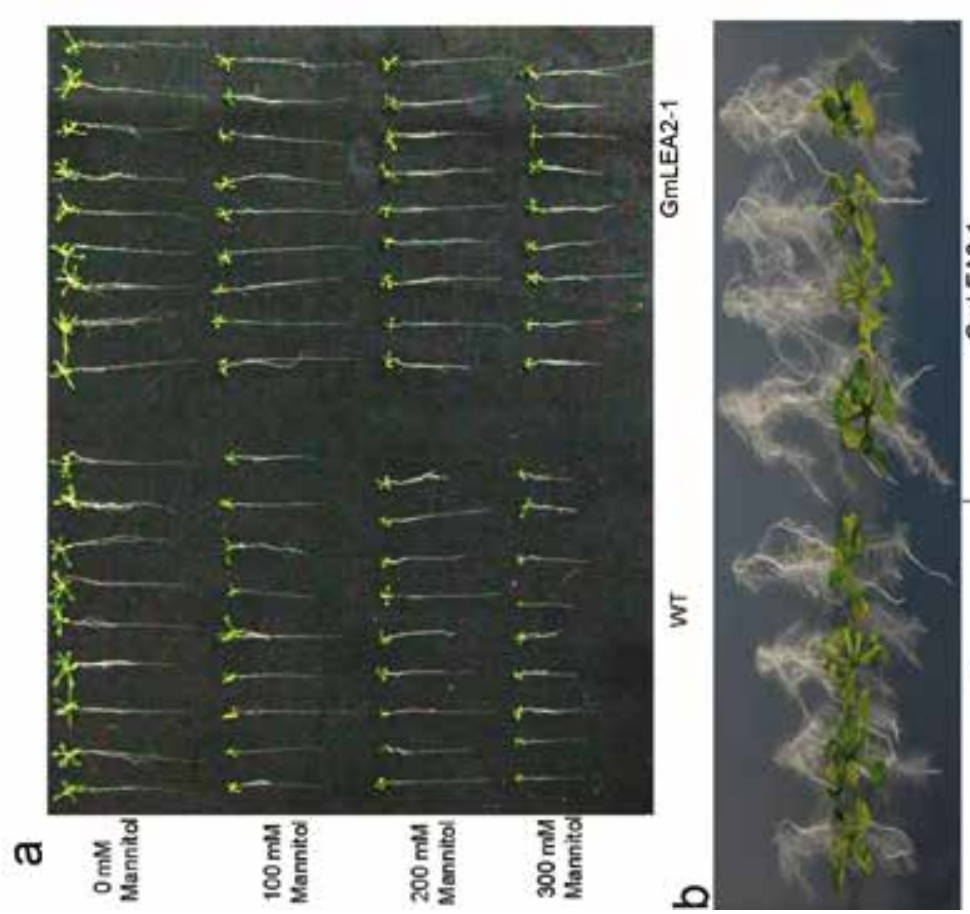

政

进舟

离䒚

三

bo응

严密要

$\overline{4}$.

on 궁

牙

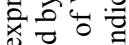

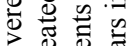

등

7 겅

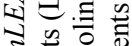

डิ

일

品.

:

可

릉

层家

这总青

Acta Biologica Hungarica 69, 2018 


\section{GmLEA2-1 overexpression in Arabidopsis increased resistance to drought}

Ten-day-old WT and transgenic seedlings were transferred into 1/2 MS medium with $0 \mathrm{mM}, 100 \mathrm{mM}, 200 \mathrm{mM}$, and $300 \mathrm{mM}$ mannitol. The transgenic seedlings overexpressed GmLEA2-1 showed a stronger growth performance than WT under high concentration mannitol stress (Fig. 3a). Transgenic lines showed a significantly stronger root growth than the WT with $200 \mathrm{mM}$ and $300 \mathrm{mM}$ mannitol stresses for 10 days (Fig. 3b).

The free proline content of WT and transgenic plants all increased after the treatment with mannitol for 10 days. However, a significantly higher increase of free proline content $(\mathrm{P}<0.05)$ was observed in the transgenic lines L25 compared with the WT (Fig. 3c). Taken together, these results indicated that GmLEA2-1 overexpression in Arabidopsis showed more drought resistance.

Table 1

Putative cis-acting regulatory elements associated with $\mathrm{ABA}$ and various stresses in GmLEA2-1 promoter region

\begin{tabular}{|c|c|c|c|}
\hline $\begin{array}{l}\text { Cis-element } \\
\text { name }\end{array}$ & Sequence & Numbers & Function \\
\hline ABRE & $\begin{array}{l}\text { ACGTG } \\
\text { ACGT }\end{array}$ & $\begin{array}{l}1 \\
4\end{array}$ & $\begin{array}{l}\text { ABA-mediated regulation of transcription. Involved in ABA } \\
\text { response }\end{array}$ \\
\hline DRE & $\begin{array}{l}\text { RCCGAC } \\
\text { ACCGAC }\end{array}$ & $\begin{array}{l}2 \\
2\end{array}$ & $\begin{array}{l}\text { DRE/CRT regulatory element involved in dehydration, cold or } \\
\text { senility responsiveness. DBF } 1 \text { and DBF } 2 \text { binding site in the } \\
\text { maize rab17 gene promoter involved in ABA induction }\end{array}$ \\
\hline CRE & GTCGAC & 4 & $\begin{array}{l}\text { DNA binding is regulated by temperature; "Core CRT/DRE } \\
\text { motif" }\end{array}$ \\
\hline $\mathrm{CBF}$ & $\begin{array}{l}\text { RYCGAC } \\
\text { GTCGAC }\end{array}$ & $\begin{array}{l}4 \\
2\end{array}$ & $\begin{array}{l}\text { Binding site of barley CBF1 and barley CBF2; Preferred } \\
\text { sequence for AP2 transcriptional activator HvCBF2 of barley; } \\
\text { "Core CRT/DRE motif"; DNA binding is regulated by temper- } \\
\text { ature }\end{array}$ \\
\hline LTRE & CCGAC & 2 & $\begin{array}{l}\text { ABA responsiveness; Involved in cold induction of BN115 } \\
\text { gene from winter Brassica napus; Light signaling mediated by } \\
\text { phytochrome is necessary for cold- or drought-induced gene } \\
\text { expression through the C/DRE in Arabidopsis }\end{array}$ \\
\hline MYB & $\begin{array}{l}\text { WAACCA } \\
\text { TAACTG } \\
\text { YAACKG } \\
\text { CNGTTR }\end{array}$ & $\begin{array}{l}4 \\
2 \\
2 \\
3\end{array}$ & $\begin{array}{l}\text { Binding site for ATMYB2, ATMYB2 is involved in regulation } \\
\text { of genes that are responsive to water stress in Arabidopsis. } \\
\text { Binding site for all animal MYB and at least two plant MYB } \\
\text { proteins ATMYB1 and ATMYB2, both isolated from } \\
\text { Arabidopsis }\end{array}$ \\
\hline MYC & CANNTG & 14 & $\begin{array}{l}\text { Binding site of ICE1 that regulates the transcription of CBF/ } \\
\text { DREB1 genes in the cold in Arabidopsis }\end{array}$ \\
\hline WRKY & TGAC & & $\begin{array}{l}\text { Binding site of WRKY } 71 \text {, a transcriptional repressor of the } \\
\text { gibberellin signaling pathway }\end{array}$ \\
\hline
\end{tabular}

$\mathrm{M}=\mathrm{C} / \mathrm{A} ; \mathrm{Y}=\mathrm{T} / \mathrm{G} ; \mathrm{B}=\mathrm{T} / \mathrm{C} / \mathrm{G} ; \mathrm{N}=\mathrm{A} / \mathrm{T} / \mathrm{G} / \mathrm{C} ; \mathrm{R}=\mathrm{A} / \mathrm{G} ; \mathrm{W}=\mathrm{A} / \mathrm{T} ; \mathrm{V}=\mathrm{A} / \mathrm{C} / \mathrm{G} ; \mathrm{K}=\mathrm{G} / \mathrm{T}$. 


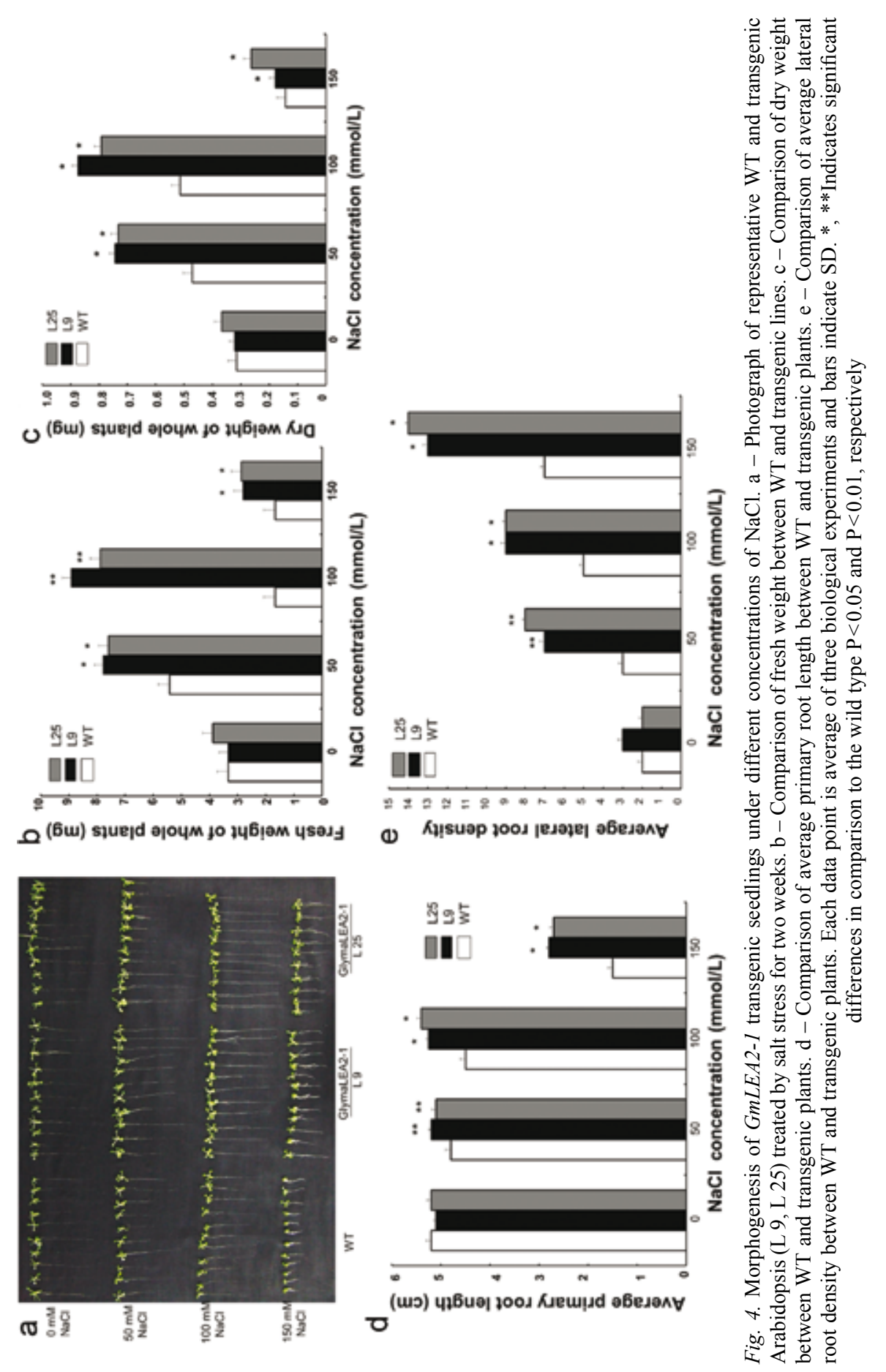

Acta Biologica Hungarica 69, 2018 


\section{GmLEA2-1 overexpression in Arabidopsis during increased resistance to salt}

When L25 and L9 transgenic seedlings and WT were grown on 1/2 MS medium with $50 \mathrm{mM}, 100 \mathrm{mM}$ and $150 \mathrm{mM} \mathrm{NaCl}$ for two weeks, the transgenic seedlings processed significantly larger leaves and longer roots than those of the WT (Fig. 4a). Consistently, the fresh and dry weights of transgenic seedlings were significantly higher than that of the WT (Fig. 4b and 4c). In addition, the transgenic lines L9 and L25 showed longer primary root length and more lateral root density than that of the WT $(\mathrm{P}<0.01)$ (Fig. 4d, 4e). These results suggests that GmLEA2-1 improves salt stress resistance of transgenic Arabidopsis.

\section{GmLEA2-1 promoter contained stress associated cis-elements}

A 2000 bp GmLEA2-1 promoter fragment (including 5'UTR) was subjected to a putative $c i s$-acting regulatory element search using the Plant Cis-acting Regulatory DNA Elements (PLACE) database [14]. In the GmLEA2-1 promoter, one ABRE-like sequence, four ABA- and dehydration-responsive ACGT-box motifs, fourteen MYC, eleven MYB-like sequences, DRE-like sequences and CRT-like sequences were all identified (Table 1).

\section{DISCUSSION}

Typical LEA proteins can retain water molecules and protect other proteins from aggregation caused by desiccation because of their highly hydrophilic properties [11]. Conversely, atypical LEA proteins have higher content of hydrophobic residues than typical LEAs. The latter have been speculated to be involved in diverse stress tolerances, although few studies have been carried out to characterize their functions [13, $18,28]$. LEA_2 group gene, GmLEA2-1, was cloned from soybean in the present study and named as a novel atypical LEA member, like SiLEA14 [28].

A previous study showed that drought, salt and root-knot nematode infection could induce $L E A$ expression, among others in hot pepper [18], tomato [31], Craterostigma plantagineum and soybean [22], tomato [10] and Arabidopsis [17] etc. In the present study, although a large difference was found in amino acid distribution between GmLEA2-1 and other atypical LEA_2 group members mentioned above, the expression of GmLEA2-1 can also be induced by PEG6000 and NaCl. We speculate that these proteins represent the same important structure domains, even though their amino acid identity was not high, and they might be similar in the regulation of their expression or the pathway involved in environmental change.

In the present study, the overexpressed GmLEA2-1 Arabidopsis plants exhibited stronger stress-tolerance to dehydration and high salt. GmLEA2-1 gene are assumed to play an important role in the pathway against abiotic stress, and this seems to be is 
in agreement with previous data reporting that the overexpression of both CaLEA6 and IbLEA14 could improve the tolerance of transgenic plants to drought and salt stress through comparable phenotype difference and biological index change [18]. Therefore, most hydrophobic LEA_2 proteins might play very important role in the stress response.

The identification of cis-acting elements in the GmLEA2-1 promoter may help obtain insight into the molecular mechanism of GmLEA2-1 function. The ABA responsive element (ABRE), which has been identified in the promoters of many ABA-inducible genes of plants such as the cotton LEA gene D-113 [24], plays a key role in ABA signaling during seed development and under abiotic stresses [15]. The drought responsive/C-repeat/low temperature response (DRE/CRT/LTRE) element was identified as the second prominent cis-element in relation to the expression of stress regulated genes in general and LEA genes in particular, which binds the CBF/ DREB1 transcription factors [15, 27]. MYC and MYB binding sites have been identified as regulatory elements associated with $\mathrm{ABA}$, drought, or cold responsiveness in plants $[1,2,26,30]$. These results suggest that GmLEA2-1 might stand under the regulation of DREB-, DBF-, CBF-, MYC- or MYB-like transcription factors in soybean.

In summary, GmLEA2-1 gene was isolated from soybean. It was induced by PEG6000 and NaCl. Overexpression of GmLEA2-1 resulted in enhanced resistance to abiotic stresse in transgenic Arabidopsis. The results described above show that GmELA2-1 plays an important role in the pathway against abiotic stress. Our results also provide further important information for the development of crop tolerance to environmental stresses. Future studies are needed to deliver insight into the relationship between function and structural domains, and the molecular mechanisms of soybean LEA genes in plant defense responses and development.

\section{ACKNOWLEDGEMENTS}

This study was supported by the "Academic Backbone" Project of Northeast Agricultural University (16XG01), National Core Soybean Genetic Engineering Project (Contract No. 2015ZX08004-002, 2015ZX08004-003) CARS-04-PSO4, and Heilongjiang Province Postdoctoral Foundation (LBHZ12047).

\section{REFERENCES}

1. Abe, H., Urao, T. Ito, T., Seki, M., Shinozaki, K., Yamaguchi-Shinozaki, K. (2003) Arabidopsis AtMYC2 (bHLH) and AtMYB2 (MYB) function as transcriptional activators in abscisic acid signaling. Plant Cell 15, 63-78.

2. Abe, H., Yamaguchi-Shinozaki, K., Urao, T., Iwasaki, T., Hosokawa, D., Shinozaki, K. (1997) Role of Arabidopsis MYC and MYB homologs in drought- and abscisic acid-regulated gene expression. Plant Cell 9, 1859-1868.

3. Banerjee, A., Roychoudhury, A. (2016) Group II late embryogenesis abundant (LEA) proteins: structural and functional aspects in plant abiotic stress. Plant Growth Reg. 79, 1-17. 
4. Battaglia, M., Olvera-Carrillo, Y., Garciarrubio, Campos, F., Covarrubias, A. A. (2008) The enigmatic LEA proteins and other hydrophilins. Plant Physiol. 148, 6-24.

5. Bhatnagar-Mathur, P., Vadez, V., Sharma, K. (2008) Transgenic approaches for abiotic stress tolerance in plants: retrospect and prospects. Plant Cell Rep. 27, 411-424.

6. Boucher, V., Buitink, J., Lin, X., Boudet, J., Hoekstra, F. A., Hundertmark, M., Renard, D., Leprince, O. (2009) MtPM25 is an atypical hydrophobic late embryogenesis abundant protein that dissociates cold and desiccation-aggregated proteins. Plant Cell Environ. 33, 418-430.

7. Cuming, A. C. (1999) LEA protein. In: Casey, R., Shewry, P. R. (eds), Seed proteins. Kluwer Academic Publishers, Dordrecht, The Netherlands, pp. 753-780.

8. Dure, L. (1993) Structural motifs in LEA proteins. In: Close, T. J., Bray, E. A. (eds), Plant responses to cellular dehydration during environmental stress. American Society of Plant Physiologists, Rockville, MD, pp. 91-103.

9. Dure, L. III, Greenway, S. C., Galau, G. A. (1981) Developmental biochemistry of cottonseed embryogenesis and germination: changing messenger ribonucleic acid populations as shown by in vitro and in vivo protein synthesis. Biochemistry 20, 4162-4168.

10. Eycken, W., Engler, J. D. A., Inze, D., Montagu, M., Gheysen, G. (1996) A molecular study of rootknot nematode-induced feeding sites. Plant J. 9, 45-54.

11. Goyal, K., Shinozaki, K. (2005) LEA proteins prevent protein aggregation due to water stress. Biochem. J. 388, 151-157.

12. Haaning, S., Radutoiu, S., Hoffmann, S. V., Dittmer, J., Giehm, L., Otzen, D. E., Stougaard, J. (2008) An unusual intrinsically disordered protein from the model legume Lotus japonicus stabilizes proteins in vitro. J. Biol. Chem. 283, 31142-31152.

13. He, S., Tan, L., Hu, Z., Chen, G., Wang, G., Hu, T. (2012) Molecular characterization and functional analysis by heterologous expression in E. coli under diverse abiotic stresses for OsLEA5, the atypical hydrophobic LEA protein from Oryza sativa L. Mol. Genet. Genomics 287, 39-54.

14. Higo, K., Ugawa, Y., Iwamoto, M., Korenaga, T. (1999) Plant cis-acting regulatory DNA elements (PLACE) database. Nucleic Acids Res. 27, 297-300.

15. Hughes, D. W., Galau, G. A. (1989) Temporally modular gene expression during cotyledon development. Genes Dev. 3, 358-369.

16. Hundertmark, M., Hincha, D. K. (2008) LEA (late embryogenesis abundant) proteins and their encoding genes in Arabidopsis thaliana. BMC Genomics 9, 118-139.

17. Imai, R., Chang, L., Ohta, A., Bray, E. A., Takagi, M. (1996) A lea-class gene of tomato confers salt and freezing tolerance when expressed in Saccharomyces cerevisiae. Gene 170, 243-248.

18. Kim, H. S., Lee, J. H., Kim, J. J., Kim, C. H., Jun, S. S., Hong, Y. N. (2005) Molecular and functional characterization of CaLEA6, the gene for a hydrophobic LEA protein from Capsicum annuum. Gene $344,115-123$

19. Kyte, J., Doolittle, R. F. (1982) A simple method for displaying the hydropathic character of a protein. J. Mol. Biol. 157, 105-132.

20. Ling, H., Zeng, X., Guo, S. (2016) Functional insights into the late embryogenesis abundant (LEA) protein family from Dendrobium officinale (Orchidaceae) using an Escherichia solisystem. Sci. Rep. 6, 39693.

21. Liu, M., Li, D. M., Wang, Z. K., Meng, F. Z., Li, Y. G., Wu, X. X., Teng, W. L., Han, Y. P., Li, W. B. (2012) Transgenic expression of ThIPK2 gene in soybean improves stress tolerance, oleic acid content and seed size. Plant cell, Tissue Organ Cult. 111, 277-289.

22. Maitra, N., Cushman, J. C. (1994) Isolation and characterization of a drought-induced soybean cDNA encoding a D95 family late embryogenesis abundant protein. Plant Physiol. 106, 805-806.

23. Menze, M. A., Boswell, L., Toner, M., Hand, S. C. (2009) Occurrence of mitochondria-targeted late embryogenesis abundant (LEA) gene in animals increases organelle resistance to water stress. J. Biol. Chem. 284, 10714-10719.

24. Narusaka, Y., Nakashima, K., Shinwari, Z. K., Sakuma, Y., Furihata, T., Abe, H., Narusaka, M., Shinozaki, K., Yamaguchi-Shinozaki, K. (2003) Interaction between two cis-acting elements, ABRE 
and DRE, in ABA-dependent expression of Arabidopsis $r d 29 \mathrm{~A}$ gene in response to dehydration and high-salinity stresses. Plant J. 34, 137-148.

25. Rodriguez-Valentin, R., Campos, F., Battaglia, M., Solorzano, R. M., Rosales, M. A. (2014) Group 6 late embryogenesis abundant (LEA) proteins in monocotyledonous plants: genomic organization and transcript accumulation patterns in response to stress in Oryza sativa. Plant Mol. Biol. Rep. 1, 198-208.

26. Simpson, S. D., Nakashima, K., Narusaka, Y., Seki, M., Shinozaki, K., Yamaguchi-Shinozaki, K. (2003) Two differed novel cis-acting elements of erd1, a clpA homologous Arabidopsis gene function in induction by deydration stress and dark-induced senescence. Plant J. 33, 259-270.

27. Thomashow, M. F. (1999) Plant cold acclimation: freezing tolerance genes and regulatory mechanisms. Annu. Rec. Plant Physiol. Plant Mol. Biol. 50, 571-599.

28. Wang, M. W., Li, P., Li, C., Pan, Y. L., Jiang, X. Y., Zhu, D. Y., Zhao, Q., Yu, J. J. (2014) SiLEA14, a novel atypical LEA protein, confers abiotic stress resistance in foxtail millet. BMC Plant Biol. 14, 290-305.

29. Xu, D. (1996) Expression of a late embryogenesis abundant protein gene, HVA1, from barley confers tolerance to water deficit and salt stress in transgenic rice. Plant Physiol. 110, 249-257.

30. Yamaguchi-Shinozaki, K., Shinozaki, K. (2005) Organization of cis-acting regulatory elements in osmotic- and cold-stress-responsive promoter. Trends Plant Sci. 10, 88-94.

31. Zegzouti, H., Jones, B., Marty, C., Lelievre, J. M., Latche, A., Pech, J. C., Bouzayen, M. (1997) Er5, a tomato cDNA encoding an ethylene-responsive LEA-like protein: characterization and expression in response to drought, ABA and wounding. Plant Mol. Bio. 35, 847-854. 